\title{
Ingestion foreign bodies in rumen and reticulum of shoats in hargeisa, Somalia: prevalence and the associated risk factors
}

\begin{abstract}
Shoats are primarily the domestic animals of Somali pastoral communities that ensure food security and economic growth of the country but recent years were decreased due to the shortage of feed and increased contaminated environment. Cross-sectional study was carried out from August 2017 to November 2017 to assess the prevalence of foreign bodies in a rumen and to identify their type and associated risk factors in the slaughtered animals at Maandeeq abattoir. A total of 500 small ruminants were examined in the study. Systematic random sampling was employed to select the animals. Out of these, 33\% (165/500) were had indigestible foreign bodies in the rumen and reticulum. The prevalence of foreign bodies was significantly $(\mathrm{P}<0.05)$ higher in goat, $40.0 \%$ $(78 / 195)$ than in sheep $28.5 \%(87 / 305)$. Odds ratio (OR) analysis indicated that goats were 1.67 times likely shown to acquire foreign body in rumen and reticulum than sheep $(\mathrm{OR}=1.670 \mathrm{CI}=1.143-2.441)$. Statistically significant difference $(\mathrm{P}<0.05)$ in the prevalence of indigestible foreign material were observed between female $(36.19 \%)$ and male $(27.57 \%)$, Besides, Significantly $(\mathrm{P}<0.05)$ higher prevalence was observed in old aged ( $>3$ years) shoats $(53.85 \%)$ than young $(<2$ years $)$ aged animals $16 \%$ as well as significantly higher prevalence was reported in thin body conditioned animals $(46.67 \%)$ than good body conditioned $(22.33 \%)$. Considering the origin of the examined animals, highly significance $(\mathrm{P}<0.05)$ prevalence was observed in urban $(53.33 \%)$ than rural area $(26.18 \%)$. Most commonly foreign bodies encountered were mixed foreign bodies $(13.4 \%)$ followed by plastic bags $(9.8 \%)$, clothes $(5.80 \%)$, robes $(2.2 \%)$, metals $(1.2 \%)$ and stones $(0.6 \%)$ due to environmental pollution at the origin of the animals that may adversely affect the overall productivity and production. Proper waste management and creation of awareness for animal owners are necessary to avoid the risk of foreign body ingestion by the small ruminates.
\end{abstract}

Volume 7 Issue 3 - 2018

\author{
Ahmed Mohamoud Omer \\ Mekelle University, College of Veterinary Medicine, Ethiopia
}

Correspondence: Ahmed Mohamoud Omer, Mekelle University, College of Veterinary Medicine, Mekelle, Ethiopia, Tel +25 I94735 I347, Email ahmedwaddani@gmail.com

Received: February 06, 20I8 | Published: May 03, 2018

Keywords: foreign bodies, maandeeq abattoir, prevalence, shoats, somalia

Abbreviations: ESGPIP, Ethiopia sheep and goat productivity improvement program; FAO, food and agricultural organization; IUCN, international union for conservation of nature and natural, LMIS, livestock marketing information system; SDRB, Somali development and reconstruction bank; SEMA, Somali and environmental management authorities; SARD, society for animal and range development

\section{Introduction}

Livestock is the backbone of the Somali's economy and supports the largest production community of the Somali people who raise their animals under harsh production system-Pastoralism. ${ }^{1}$ Over $70 \%$ of the Somali population subsists in pure pastoralism. Livestock contribute $60 \%$ to the gross domestic product (GDP) and $80 \%$ to the value of the national exports the pastoral livestock production system. Its contribution is a net value added to the GDP since it comes from rangeland resources produced and marketed with little input from outside the system. ${ }^{1,2}$ Somalia is one of the largest livestock population in Africa those livestock are mainly Sheep and goats. ${ }^{1}$ Although in Somalia, the pasture and supplementary concentrate feed for intensive livestock management are limited and expensive, as result, most livestock farmers adopt free-range management system in the urban and semi-urban communities where their animals, mostly sheep and goats, scavenge for food, often going into refuse dumps, which are around the towns. ${ }^{3}$ However, Sheep and goats are highly selective feeders and ingest significantly less amount of foreign bodies as compared to cattle. ${ }^{4}$ Ingestion of large quantities of indigestible materials occurs in sheep and goats during periods of drought, food scarcity, nutritional deficiency, pica and massive environmental pollution as reported in the Somaliland meat inspection workers in Hargeisa. ${ }^{5,6}$ Indigestible foreign bodies in the rumen and reticulum predisposed by environmental pollution are fast becoming a major global problem in ruminants worldwide. ${ }^{7}$ Different studies have shown that ruminants reared in urban and sub-urban areas have high probability to ingest indigestible materials such as plastic, cloth, wire, leather and metal. ${ }^{8}$ Ingestion of indigestible foreign bodies by animals is mainly associated with environmental pollution due to absence of recycling industries, cleaning of environment cultures, improper disposal of plastic bags; free grazing animals eat plastic bags especially in towns and villages. These plastic bags are indigestible and their accumulation in the rumen of grazing animals may lead to adverse effect on health ${ }^{9}$ plastic bags resist to biodegradation and pollute for decades and centuries and pose great risk to human health and environment. ${ }^{10}$

The presence of foreign bodies in the rumen and reticulum hampers the absorption of volatile fatty acids and consequently reduction in the 
rate of animal fattening ${ }^{11}$ the perforation of the wall of the reticulum can also allow leakage of ingest and bacteria which contaminates the peritoneal cavity, resulting in local or diffuse peritonitis. ${ }^{12}$ Clinical indigestible foreign body impaction is characterized by pale mucous membrane, reduction of milk yield, complete cessation of rumination, impacted rumen, atony, reduced rumen motility, faeces become scant and inappetance..$^{13}$ In Somalia, ruminants are kept under extensive farming system and they are more likely to be exposed to ingestion of indigestible materials from different sources due to high environmental contamination with plastic bags and other materials. Despite the free grazing of ruminants in contaminated environments, there is limited information about prevalence and type of foreign bodies ingested by ruminants at national level in general and in Hargeisa in particular. Therefore, this study determined the prevalence of rumen and reticulum foreign bodies, their types and potential risk factors associated with their occurrence in sheep and goats in Somalia. The aim of the present study could help environmental activist, livestock owners, veterinarians and policy makers to recognize the impact of indigestible foreign bodies on small ruminant's health and productivity in the Somalia. This study also could mentioned most rank associated risk factors of indigestible foreign bodies in rumen and reticulum of sheep and goats in Somalia and also this study would help how to reduce all associated risk factors of indigestible foreign bodies in rumen and reticulum of shoats Somalia.

\section{Materials and methods}

\section{Study area}

Hargeisa is the second largest city in Somalia, located in the Woqooyi Galbeed region. It is the capital of Somaliland, and located in a valley in the north western section of the country. The city is situated in a mountainous area, the temperature ranges between $13^{\circ} \mathrm{C}$ and $32^{\circ} \mathrm{C}$ degrees Celsius (55 and 89 degrees Fahrenheit). It has a semi-arid climate and it is warm in winters and hot in summers. The city receives the bulk of its precipitation between the months of April and September, averaging just less than $400 \mathrm{~mm}$ of rainfall annually. It has high livestock population density and it has second largest livestock market of Somalia. Furthermore, it has two abattoirs which had governmental owned and each day were slaughtered more than 1200 shoats, 150 camels 100 cattle by Hallal method of slaughtering and all animals were used for local consumption. ${ }^{14,15}$

\section{Study design}

A cross-sectional study was carried out on sheep and goats slaughtered in Maandeeq slaughter house at Hargeisa city in Somalia from August 2017 to November 2017 for the study area to assess the prevalence of rumen and reticulum foreign bodies and to identify the type of foreign bodies and their associated risk factors in rumen of shoats presented for slaughter.

\section{Sample size}

The total number of sheep and goats required for this study was calculated based on the formula given by Thrusfield. ${ }^{16}$ For an infinite population with $95 \%$ confidence level, $5 \%$ desired absolute precision and there was no previous study on prevalence of rumen and reticulum foreign bodies of sheep and goats slaughtered at Maandeeq slaughter house in Hargeisa, so the expected prevalence was used $50 \%$. Therefore, the sample size was calculated by using following
Thrusfield formula: $\mathrm{n}=1.962\{\mathrm{P} \exp (1-\mathrm{Pexp})\} / \mathrm{d} 2$ Where: $\mathrm{n}=$ required sample size, $\mathrm{P} \exp =$ Expected prevalence of foreign body in shoats $(50 \%), d=$ Desired absolute precision level at $95 \%$ confidence level $(5 \%) .1 .96=$ the value of $Z$ at $95 \%$ confidence level. Total sample size was 384 animals however; Sample size was to increase the precision 500 animals were examined.

\section{Sampling}

According to the reports of LMIS the average sheep and goats slaughtered in Maandeeq Slaughter house were 1200 animals. $^{15}$ Animals used for this study were selected through Modified systematic random sampling technique; the slaughter house was visited 20 days consecutively period on September and total animals slaughtered during the project were 24000 animals. Although, during each visit 25 animals were selected by picking every 48 animals to be slaughtered irrespective of species until the desired number 25 is obtained.

\section{Data collection}

Ante mortem examination: The selected animals were examined to determine the sex, age, the body condition and their place of origin before slaughter. Age of the sheep and goats were categorized into young ( $<2$ years), adult ( $2-3)$ years) and old ( $>3$ years) based on dentition eruption, ${ }^{17} \operatorname{sex}($ female and male) and Body condition of sheep and goats were recorded as thin, medium and good based on the appearance of the animal and manual palpation of the spinus and transverse processes of the lumbar vertebrae according to ESGPIP ${ }^{18}$ while the origin of the animals categorised rural, pre-urban and urban based on categorisation of land in (SEMA) Somali Environmental Management Authorities. ${ }^{19}$ During Ante mortem examination each animal selected for the study was further identified by providing a unique identification number, by using ink on its gluteal muscle, that could be used for both ante-mortem and post-mortem examinations of the animal.

\section{Post-mortem examination}

Immediately after slaughter in the evisceration stage, the forestomach (comprising the rumen and reticulum) were carefully removed from the abdominal cavity and placed in a container in such a way as to minimize spillage of contents from the different chambers. Each rumen and reticulum was opened individually by incision and given a thorough macroscopic examination by using visual inspection, palpation and magnetic metal for detection of both metallic and non metallic foreign bodies in the rumen and reticulum. Any foreign bodies obtained during inspection were washed with water to remove adhering feed materials and identified the type of foreign body.

\section{Data management and analysis}

The data was entered and managed in a Microsoft Excel spread sheet and analysed by using STATA version 12. Descriptive statistics was used to determine frequencies and overall prevalence. The prevalence of indigestible foreign bodies was determined as a proportion of affected animals out of the total animal examined. The differences or association between risk factors were analysed by binary logistic regression and $95 \%$ confidence interval of the OR and P-values were used to describe statistical significance associations. The association is judged as significant when P- value is less than 0.05 . 


\section{Results}

\section{Prevalence of foreign body in relation to animal species}

A total of 500 animals (305 sheep and 195 goats) were examined for presence of indigestible foreign bodies in their rumen. Out of these, $33 \%(165 / 500)$ were found to have various types of indigestible foreign bodies in the rumen. Of the 305 sheep and 195 goats examined, the indigestible foreign body were found at $28.5 \%(87 / 305)$ and $40.0 \%(78 / 195)$, respectively, there was significant difference $(\mathrm{P}<$ $0.05)$ between the two animal species. This result indicates that goats were $1.670(\mathrm{OR}=1.670, \mathrm{CI}=1.143-2.441)$ times more likelihood to acquire foreign body than sheep (Table 1).

\section{Prevalence of foreign body in relation to animal sex}

Among the total of 165 positive cases of foreign body, out of these
$36.19 \%(114 / 315)$ were occurred in female while $27.57 \%(51 / 185)$ were found in male animals. There was statistical significant difference between the male and females $(\mathrm{P}<0.05)$. The odd of foreign body occurrence in females were 1.490 times more susceptible than males $(\mathrm{OR}=1.490, \mathrm{CI}=1.003-2.214)($ Table 1$)$.

\section{Prevalence of indigestible rumen foreign bodies in different age groups}

From total of 500 sheep and goats examined, higher foreign body prevalence was observed in the older animals ( $>3$ years) $53.85 \%(105 / 195)$ followed by $2-3$ years $22.22 \%(40 / 180)$ and lower prevalence was observed in young age animals $(<2$ years $)$ $16 \%(20 / 125)$ There was statistical significant difference $(\mathrm{P}<0.05)$ between the difference age categories. The findings indicate that older age were 0.245 times more likely to get foreign body than younger $(\mathrm{OR}=0.245, \mathrm{CI}=)($ Table 1$)$.

Table I Prevalence of different foreign body and binary logistic regression analysis of factors associated foreign body ingestion

\begin{tabular}{|c|c|c|c|c|c|c|c|}
\hline \multicolumn{2}{|c|}{ Risk factors } & \multirow{2}{*}{$\begin{array}{l}\text { Animals examined } \\
305\end{array}$} & \multirow{2}{*}{$\begin{array}{l}\text { Examined foreign bodies } \\
87\end{array}$} & \multirow{2}{*}{$\begin{array}{l}\text { Prevalence \% } \\
28.52 \%\end{array}$} & \multirow[t]{2}{*}{ Odd ratio } & \multirow[t]{2}{*}{$(95 \% \mathrm{Cl})$} & \multirow[t]{2}{*}{ P-value } \\
\hline & Sheep & & & & & & \\
\hline species & Goats & 195 & 78 & $40.00 \%$ & 1.67 & I.143-2.44I & 0.008 \\
\hline \multirow{3}{*}{ Sex } & Male & 185 & 51 & $27.57 \%$ & & & \\
\hline & Female & 315 & 114 & $36.19 \%$ & 1.49 & $|.003-2.2| 4$ & 0.048 \\
\hline & $>3$ years & 195 & 105 & $53.85 \%$ & 0.245 & $0.156-0.384$ & \\
\hline \multirow[t]{2}{*}{ Age } & 2-3years & 180 & 40 & $22.22 \%$ & 0.163 & $0.094-0.284$ & 0 \\
\hline & $<2$ years & 125 & 20 & $16.00 \%$ & & & \\
\hline Total & & 500 & 165 & $33.00 \%$ & & & \\
\hline
\end{tabular}

\section{Prevalence of foreign bodies in different body condition score of the Shoats}

The overall foreign body prevalence in the thin, medium and good body conditioned group of animals was $46.67 \%, 40.00 \%$ and $22.23 \%$ respectively (Table 2). There was strongly statistical significant association difference $(p<0.05)$ in the event of foreign body in the three groups of body conditions score of the shoats. The foreign body occurrence in thin body condition scored animals were 3.044 times more likely than animals which have good body condition score $(\mathrm{OR}=3.044, \mathrm{CI}=1.561-5.936)$ (Table 2).

Table 2 Prevalence of different foreign body and binary logistic regression analysis of factors associated foreign body ingestion

\begin{tabular}{|c|c|c|c|c|c|c|c|}
\hline \multicolumn{2}{|c|}{ Risk factors } & \multirow{2}{*}{$\begin{array}{l}\text { Animals examined } \\
215\end{array}$} & \multirow{2}{*}{$\begin{array}{l}\text { Examined foreign bodies } \\
48\end{array}$} & \multirow{2}{*}{$\begin{array}{l}\text { Prevalence \% } \\
22.33 \%\end{array}$} & \multirow{2}{*}{$\begin{array}{l}\text { Odd ratio } \\
-\end{array}$} & \multirow{2}{*}{$(95 \% \mathrm{CI})$} & \multirow[t]{2}{*}{ P-value } \\
\hline & Good & & & & & & \\
\hline \multirow[t]{3}{*}{ BCS } & Medium & 240 & 96 & $40.00 \%$ & 2.319 & $|.536-3.50|$ & 0 \\
\hline & Thin & 45 & 21 & $46.67 \%$ & 3.044 & $|.56|-5.936$ & \\
\hline & Rural & 175 & 72 & $26.18 \%$ & - & - & \\
\hline \multirow[t]{2}{*}{ Source } & Suburban & 135 & 45 & $33.33 \%$ & $1.4 \mathrm{I}$ & $.901-2.206$ & 0 \\
\hline & Urban & 90 & 48 & $53.33 \%$ & 3.222 & I.967-5.279 & \\
\hline Total & & 500 & 165 & $33.00 \%$ & & & \\
\hline
\end{tabular}

Prevalence of rumen foreign bodies in Shoats from different to original area

Slaughtered sheep and goats at Maandeeq slaughter house was came from three different sources like urban, pre-urban and rural areas and the highest frequencies of rumen indigestible foreign body observed in sheep and goat originated from urban area $53.33 \%$
(48/175) flowed by suburban area 33.33\% (45/135) while the lowest from rural area $26.18 \%(72 / 90)$. There was a statistically significant difference $(\mathrm{P}<0,05)$ among the origin of animals. The odd ratio indicate that animals were lives in the urban area were 3.222 times more likely having a chances to acquire foreign body than animals live in rural area (Table 2). 


\section{Types of frequency occurrence of indigestible rumen foreign bodies}

Types of indigestible rumen foreign materials found in sheep and goats slaughtered were mixed foreign body $(13.4 \%)$ followed by plastic bags $(9.8 \%)$, clothes $(5.80 \%)$, robes $(2.2 \%)$, metals $(1.2 \%)$ and stones $(0.6 \%)$.

\section{Discussion}

This study showed an overall rumen indigestible foreign body prevalence of $33 \%(165 / 500)$ of shoats slaughtered at Maandeeq abattoir in Somalia. This finding is relatively higher compared to the, $10.8 \%$ and $14 \%$ prevalence rates previously reported in Kenya and South eastern Ethiopia respectively, ${ }^{20,21}$ however, it has agreement with study conducted by Fasil ${ }^{22}$ who reported prevalence of $30.7 \%$ in Jigjiga, Eastern Ethiopia. Besides, the reported prevalence of this study is much lower compared to the higher prevalence rate $95 \%, 87 \%$ and $58.1 \%$ were reported in animals in urban areas of Nigeria, South Darfur and eastern Ethiopia respectively $(22 ; 9 ; 8)$ This difference in the prevalence of foreign bodies between different origins of the animals slaughtered may be associated with differences in animals' management system, and the extent of foreign body management between different study areas. In this study significant higher prevalence of foreign body was observed in goats $40 \%$ (78/195) than sheep $28.52 \%$ (87/305) slaughtered at study area. it has disagreement with study conducted by Fasil ${ }^{22}$ who reported prevalence of sheep $34.40 \%$ and goat $27 \%$ in Jigjiga, Eastern Ethiopia. However, the reported prevalence of this findings is much lower compared to the higher prevalence rate $56.5 \%$ sheep and $59.5 \%$ goat were reported in eastern Ethiopia ${ }^{8}$ this difference in prevalence of animal species due to the difference animal origin because the goats in Hargeisa mostly reared in the urban and peri-urban areas for the purpose of milk production and they have not yet natural pastures as compared the rural area because the polluted pasture are more in urban and preurban areas then the rural area.

In our study significantly $(\mathrm{P}<0.05)$ higher prevalence of foreign body was observed in female $(36.19 \%)$ than male $(27.57 \%)$.it has agreement with study conducted by Teshome et al., ${ }^{20}$ who have reported prevalence rate $27.9 \%$ in female and $23.9 \%$ in male at Southeastern Ethiopia. This sex dependent difference in the prevalence of the foreign body in the rumen may be attributed to hormonal changes and increased appetite due to nutritional demands during estruses, pregnancy and lactation in female animals. Furthermore, females generally have a longer lifespan than males, as livestock farmers normally do not sell. There was statistical significant difference between the age categories of the animals though old age had a higher prevalence $(53.85 \%)$, followed by adult $(22.22 \%)$ and lowest in young age $(16 \%)$ it has agreement with study conducted by Teshome et al. ${ }^{20}$ at South-eastern Ethiopia. Besides, it has disagreement with study conducted by ${ }^{20}$ who reported higher prevalence in the 2-3 years old age group (37.5\%) followed by those in the 1-2 year old age group $(24.1 \%)$ and absence of foreign material in animals older than 4 years at Kenya. They attributed their findings to the gradual ingestion of indigestible materials over prolonged periods of time as the animal ages.

In this study significantly higher prevalence rate observed for indigestible rumen and reticulum foreign bodies in sheep and goats in poor body condition followed by medium and thin body condition and disagrees with previously reported low prevalence rates in animals in good body condition reported at Kenya by Otsyina et al., ${ }^{19}$ similarly this study was agrees with previously reported high prevalence rates in animals in poor body condition followed by medium and thin body condition. $^{21,22}$ This may be because of thin body condition animals consuming without selection to compensate there energy balance. As a result poor body condition of animals with indigestible foreign bodies was attributed to reduction in volatile fatty acids absorption from rumen and this result in inappetance, abdominal distension, reduced weight gain, lack of defecation with consequent emaciation and recumbence. The significantly higher prevalence rate observed in this study for foreign bodies in animals from urban area 53.33\% flowed by pre-urban and rural area and disagree higher prevalence rate $95 \%$ and $87 \%$ of previously reported in animals in urban areas of Nigeria and South Darfur, respectively ${ }^{9,23}$ This difference in prevalence may be due to the differences in origin of the animals slaughtered accompanied by feed availability and the type of waste management system between the study areas. This study revealed the mixed of indigestible foreign body have higher frequency of occurrence followed by plastics, clothes, robes, metals and Stones. This finding is in general agreement with various reports from different areas of east African country, in Ethiopia, ${ }^{24,25} \mathrm{Kenya}^{20}$, Uganda ${ }^{26,27}$ and Africa. ${ }^{27}$ This indicates the widespread use of plastic bags in these areas and environmental pollution due to their improper disposal of types of foreign bodies.

\section{Conclusion and recommendations}

Rumen and reticulum foreign bodies have great economic significance associated with not only mortality but also reduce production and productivity of sheep and goats. Such kind of problem is common in developing countries like Somalia where the standard of animal management is unsatisfactory. This study showed an overall prevalence of $33 \%$ of foreign bodies in small ruminant. Statistically significant $(\mathrm{P}<0.05)$ higher prevalence was reported in goats than sheep slaughtered at Maandeeq slaughter house. According to this study species, sex, age groups, body condition score and origin of animals are the considered risk factors for the occurrence of foreign bodies in sheep and goat in the study area and all had statistical significance. Although, the types of indigestible rumen foreign materials found in shoats slaughtered was mixed foreign body (13.4\%) followed by Plastic bags, Clothes, robes, metals and Stones.

Based on the above conclusion the following recommendations are forwarded:

i. Creating awareness for animal owners to keep their animals away from the contaminated area.

ii. Animals should be supplied with sufficient feed in order to mitigate the problem of ingestion of foreign bodies.

iii. Environmental pollution should be reduced by proper management of waste which reduces the chance of ingestion of indigestible foreign bodies.

iv. Policy makers are also expected to formulate a legally binding regulation towards reducing environmental pollution.

v. Further research should be made to emphasize the importance of the problem and address the prevention and control measures in detail. 


\section{Acknowledgements}

I would like to thank my advisor Dr. Enquebaher Kassaye for his valuable comments, suggestions and guidance of my thesis and I would like to thank the Mekelle University, College of Veterinary Medicine for providing me a learning platform also I would like also to thank all staffs at Maandeeq abattoir for their allowance of this study to be conducted in their abattoir and cooperation during sample collection. Finally I would like to thank all my family specially my Mother Faduma Mohamed and my Father Mohamoud Omer (Dr. Jeenicade) for their facilitating of my all achievements.

\section{Conflicts of interest}

I declare no conflict of interest.

\section{References}

1. Somali development and reconstruction bank (SDRB). Livestock and Agriculture. 2016.

2. Ahmed A. Livestock production in Somalia emphsoncoms. Nomadic peoples. 2011.

3. Saeed I, Adan A, Hashi A, et al. National Livestock Policy. Somaliland livestock policy. 2016

4. Desiye T, Mersha C. Study on Rumen and Reticulum Foreign Bodies in Cattle Slaughtered at Jimma Municipal Abattoir, South West Ethiopia. American-Eurasian Journal of Scientific Research. 2012;7(4):160-167.

5. Elmi A. SOMALIA'S DEGRADING ENVIRONMENT Causes and Effects of Deforestation and Hazardous Waste Dumping in Somalia. Royal Institute of Technology. 2010.

6. FAO. Environmental health situation analysis in Somalia. 2011

7. Kumar V, Dhar P. Foreign body impaction in a captive Sambar (Rusa unicolor). Vet World. 2013;6(1):49-50

8. Negash S, Sibhat B, Sheferaw D. A postmortem study on indigestible foreign bodies in the rumen and reticulum of ruminants, eastern Ethiopia. Onderstepoort J Vet Res. 2015;82(1):01-05.

9. Ghurashi M, Seri H, Bakheit A, et al. Effect of surgical removal of foreign body from goat's rumen with special reference to the prevalence of foreign body in goats in Southern Darfur. Australian Journal Basic Applied Science. 2009;3(2):664-668

10. Ramaswamy, V. and Sharama, HR. Plastic bags treat to environmental and cattle health. A retro perspective study from Gondar city of Ethiopia. The IOAB Journal Special Issue on Environmental Management for Sustainable Development, 2011;2(1):7-12.

11. Bassa, K, Tesfaye W. Study on rumen and reticulium foreign bodies in cattle slauthered at WolaitaSodo municipal Abattoir. Ethoipia. Int $J$ Adv Multidiscip Res. 2017;4(1):11-19.
12. Anwar K, Khan I, Aslam A, et al. Prevalence of indigestible rumen and reticulum foreign bodies in Achai cattle at different regions of Khyber Pakhtunkhwa. ARPN Journal of Agricultural and Biological Science. 2013;8(8):580-586.

13. Semieka M. Radiography of unusual foreign body in ruminants. Vet World. 2010;3(10):473-475

14. Ahmed Jeenyocade. Field report of animal slaughtered in Wajaale, Hargeisa and Berbera slaughter houses. Sheikh technical Veterinary School.2017;13.

15. LMIS. Animal slaughtered for local consumption in Somaliland. 2017.

16. Thrusfield M. Veterinary epidemiology. 3rd ed. Blackwell Science limited, Oxford: UK; 2005. p. 229-246.

17. Yami A, Merkel RC. Sheep and Goat production Handbook for Ethiopia. 2008. p. 39-40.

18. Abegaz S, Awgichew K. Estimation of weight and age of sheep and goats. ESGPIP (Ethiopia Sheep and Goat Productivity Improvement Program) Technical Bulletin.23. 2009.

19. IUCN Eastern Africa. Country Environmental Profile for Somalia. 2006.

20. Otsyina H, Nguhiu-Mwangi J, Mogoa E, et al. Prevalence of indigestible rumen foreign bodies in sheep and goats at Dagoretti and Kiserian abattoirs, Kenya. International Journal of Veterinary Science. 2015;4 (2):75-80.

21. Teshome E, Abdela N, Hassan A. Post mortem Study on Indigestible Foreign Bodies in Rumen and Reticulum of Ruminants Slaughtered at Asella Municipal Abattoir, South eastern Ethiopia. Journal of Veterinary Science \& Technology. 2017;8:436.

22. Fasil N. Assessment of Sheep and Goat Foreign Bodies in Rumen and Reticulum in the Jigjiga Municipal Abattiar. Advances in Dairy Research. 2016;4:157

23. Remi-Adewunmi BD, Gyang E, Osinowo AO. Abattoir survey of foreign body rumen impaction small ruminants. Nigerian Veterinary Journal. 2004:25(2):32-38

24. Abdela N, Deressa FB, Teshome E. et al. Prevalence of Indigestible Foreign Bodies in the Rumen and Reticulum of Sheep Slaughtered at Jimma Municipal Abattoir, South western Ethiopia. Global Journal of Medical Research. 2017;2:2-10.

25. Mekuanint S, Alemneh T, Asredie T. Indigestible Rumen Foreign BodiesCauses of Rumen Impaction in Cattle, Sheep and Goats Slaughtered at Addis Ababa Abattoir Enterprise, Ethiopia. J Veter Sci Med. 2017;5(1):5.

26. Okot-Okumu J, Nyenje R. Municipal solid waste management under decentralisation in Uganda. Habitat International. 2011;35(4):537-543.

27. Bauer C, Christe KL. Oropharyngeal conditions. Pocket Handbook of Nonhuman Primate Clinical Medicine. 2012;1:69.

28. Rayne $\mathrm{S}$. The need for reducing plastic shopping bag use and disposal in Africa. African Journal of Environmental Science and Technology. 2008;3(3):167. 